Article

\title{
Comparison of Neutral Compound Extraction from Archaeological Residues in Pottery Using Two Methodologies: A Preliminary Study
}

\author{
Eleanora A. Reber (D)
}

check for updates

Citation: Reber, E.A. Comparison of Neutral Compound Extraction from Archaeological Residues in Pottery Using Two Methodologies: A Preliminary Study. Separations 2021, 8, 6. https://doi.org/10.3390/ separations 8010006

Received: 30 November 2020 Accepted: 2 January 2021 Published: 6 January 2021

Publisher's Note: MDPI stays neutral with regard to jurisdictional clai$\mathrm{ms}$ in published maps and institutional affiliations.

Copyright: () 2021 by the author. Licensee MDPI, Basel, Switzerland. This article is an open access article distributed under the terms and conditions of the Creative Commons Attribution (CC BY) license (https:// creativecommons.org/licenses/by/ $4.0 /)$.
Anthropology Department, UNC Wilmington, 601 S. College Rd., Wilmington, NC 28403, USA; rebere@uncw.edu; Tel.: +1-910-962-7734

\begin{abstract}
This study compares chloroform/methanol extraction and acidic methanol extraction of neutral compounds in absorbed lipid pottery residues from fourteen archaeological sherds. Previous studies have established that fatty acid extraction is more effective with acidic methanol extraction. This study suggests that acidic methanol extraction of neutral compounds, including sterols, alkanols, alkanes, and terpenoids, is more effective than or comparable to chloroform/methanol solvent extraction in most cases. The acidic methanol method extracts sterols, terpenoids, and alkanes more effectively than or comparably to chloroform/methanol extraction.
\end{abstract}

Keywords: pottery residue analysis; organic residue analysis; gas chromatography/mass spectrometry; extraction methods; neutral compounds; biomarkers

\section{Introduction}

Extraction and analysis of absorbed lipid residues from archaeological pottery allow for a partial reconstruction of archaeological pottery use deriving directly from biomolecular evidence [1-11] and many others. The technique has been refined in various ways since its introduction in the 1990s. The original standard extraction methodology for these residues involved solvent extraction utilizing either 2:1 $v / v$ chloroform/methanol or 2:1 $v / v$ dichloromethane/methanol $[7,9,12,13]$. This extraction method removes lipids from pottery effectively but incompletely, leaving a portion of the residue bound to the ceramic matrix. This is sometimes known as the 'bound insoluble' portion of the residue [12-17]. Bound insoluble residues are believed to include polymerized fatty acids, compounds linked to polymerized organic material, and compounds directly bonded to the ceramic matrix by interaction between their functional group and metallic or other ions within the pottery [12-17].

Of late, several extraction methodologies have been developed that increase yields of extracted fatty acids from pottery samples by utilizing acidic or alkali solutions during the extraction procedure. These remove more lipids from the ceramic matrix, decreasing the amount of lipids remaining in the bound insoluble fraction $[14,16,18]$. In particular, the acidic methanol extraction method proposed by Correa-Ascencio and Evershed [18] provides many benefits in residue extraction and analysis. This extraction method permits higher yields of extracted fatty acids from the ceramic matrix and in particular of isoprenoid and branched fatty acids. In addition, the decreased time spent in laboratory preparation and instrumental runtime permits quicker, cheaper analysis with higher throughputs [18].

Neutral compounds, such as sterols, terpenoids, alkanols, and alkanes, comprise many of the biomarkers useful in the interpretation of residues, and especially of plant products $[6,19]$. Neutral compounds are less abundant in absorbed residues than fatty acids, and their presence in the bound insoluble portion of residues during solvent extraction has not been extensively discussed. 
Neutral compounds, however, are useful in the detection of plant products. Plant products are an important part of the human diet, and comprise the majority of the diet in some cultures [20-25] and many others. Neutral compounds are therefore important in interpreting the complete range of resources processed in pottery. Given this importance, the effectiveness of the extraction of neutral compounds should be considered when comparing extraction methods. Neutral compounds are known to be extracted using the acidic methanol method [18], but no direct comparison has been made between the extraction of neutral compounds using acidic methanol extraction and chloroform/methanol extraction.

Such a comparison would assist residue laboratories in determining which extraction method to utilize, especially in projects interested in the interpretation of plant products in organic residues. If acidic methanol extraction removes neutral compounds from the ceramic matrix more effectively or equivalently to chloroform/methanol extraction, the acidic extraction methodology can be used as a single screening and interpretive step. A secondary chloroform/methanol extraction would only be required for the reconstruction of acyl lipids in the residue if required for interpretation [18]. If chloroform/methanol extraction removes neutral compounds from the ceramic matrix more effectively than acidic methanol extraction, then a secondary chloroform/methanol extraction would be needed for any residue-containing sample in which neutral compounds are of interpretive interest. The latter would be more time-consuming for laboratories, and decrease the overall throughput of residue samples in projects interested in the interpretation of neutral biomarkers.

This study directly compares the extraction of neutral compounds from a small number of archaeological pottery samples using both chloroform/methanol and acidic methanol extraction. Since this is a preliminary study, further extraction comparisons with a wider geographic and temporal range of samples will be needed to conclude more broadly which method is most useful for the extraction of neutral compounds from pottery residues. The goal of this study is to provide a framework for such future analysis and to highlight the importance of the extraction of neutral compounds in the detection of plant products in pottery residues.

\section{Materials and Methods}

The chloroform/methanol extraction methodology is based on well-known lipid extraction methods for biological samples [26,27]. This method has been used on archaeological pottery residues since the mid-1990s. In general, 2:1 $v / v$ chloroform: methanol or $v / v$ dichloromethane/methanol is used to extract a powdered sherd, producing a total lipid extract (TLE) that includes extracted acyl lipids, waxes, terpenoids, free fatty acids, and free neutral compounds. If desired, a portion of the extracted residue may then be saponified, producing two additional fractions for analysis: a neutral fraction, including saponified and free neutral lipids such as sterols, alkanols, alkanes, and terpenoids; and a fatty acid fraction, including all saponified and free fatty acids. Sample size can vary from less than $2 \mathrm{~g}$ of sherd through larger sample sizes. The method preserves the structure of acyl lipids, which allows the evaluation of the overall preservation of the lipids in the total lipid fraction and the identification of high molecular weight lipids, such as those present in insect waxes. The two saponified fractions, when used, permit the quantification of neutral and fatty acid fractions in the lipid extract.

Figure 1 provides an overview of chloroform/methanol and acidic methanol extraction methods used in this study. Chloroform/methanol extraction used $10 \mathrm{~mL} \mathrm{2:1} \mathrm{v} / \mathrm{v}$ chloroform/methanol for every $2 \mathrm{~g}$ of powdered sherd. Samples were ultrasonicated for $2 \times 20 \mathrm{~min}$, with a $10 \mathrm{~min}$ rest/cooling period. Samples were centrifuged at $2000 \times g$ rpm for $20 \mathrm{~min}$; supernatants were then filtered using ashed, solvent-washed glass filter paper $(1.5 \mu \mathrm{L}$ mesh) to remove the remaining fine particles from the residue-impregnated solvent. The clean solvent/residue mixtures were evaporated under $\mathrm{N}_{2}$ gas and mild heat to dryness. Approximately $60 \%$ of each TLE was saponified with $2 \mathrm{~mL} \mathrm{NaOH} / \mathrm{methanol}$ and heated at $75^{\circ} \mathrm{C}$ for $1 \mathrm{~h}$. The saponified residues were extracted with $3 \times 2 \mathrm{~mL}$ hexane, 
which were blown to dryness using mild heat and $\mathrm{N}_{2}$ gas to produce the neutral fractions. The remaining hexane-extracted residues were acidified to $\mathrm{pH} 3-4$ with $2 \mathrm{M} \mathrm{HCl}$, and then extracted with $3 \times 2 \mathrm{~mL}$ hexane to produce the fatty acid fractions. These were evaporated to dryness using mild heat and $\mathrm{N}_{2}$ gas.

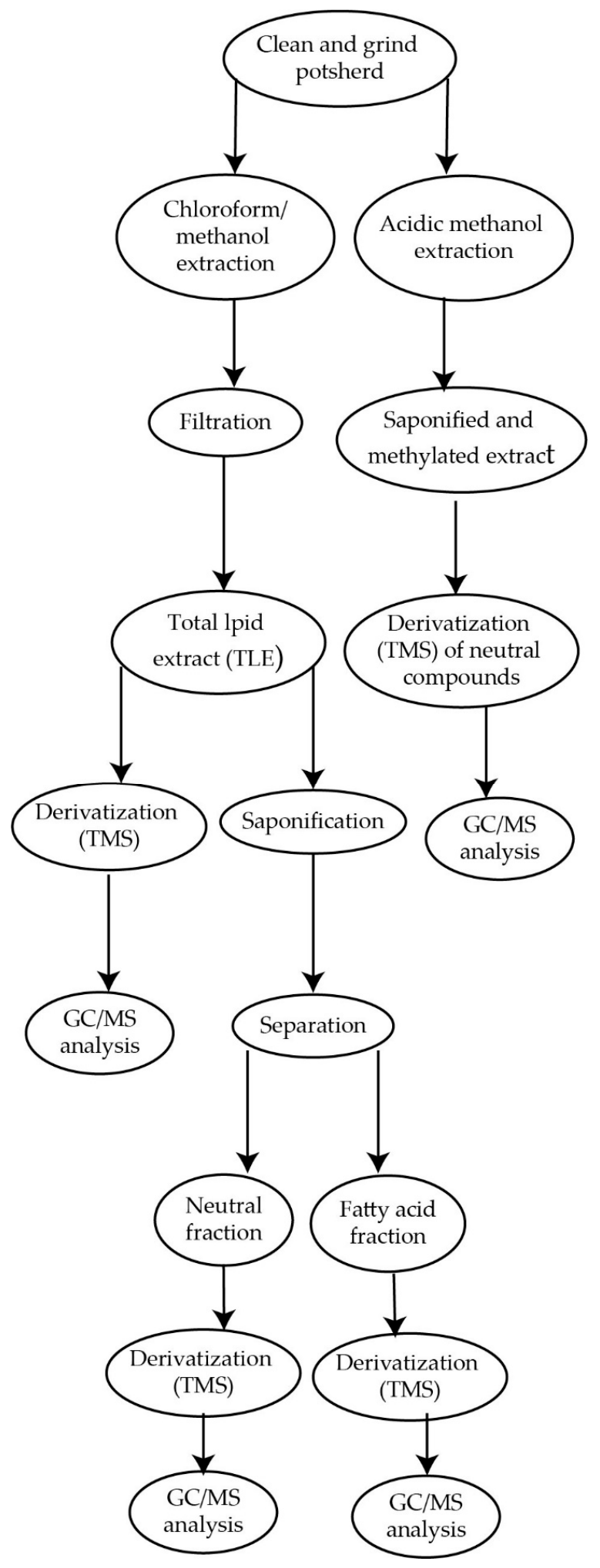

Figure 1. Extraction methods used in this paper. 
Acidic methanol extraction was developed by Correa-Ascencio and Evershed [18]. A $2 \%$ to $4 \% \mathrm{H}_{2} \mathrm{SO}_{4} /$ methanol solution extracts the powdered sherd. The process simultaneously extracts and saponifies lipids in the ceramic matrix, breaking apart acyl lipids, waxes, and other saponifiable compounds, producing a single fraction containing both fatty acids ands and neutral lipids. Sample size is $2 \mathrm{~g}$ of sherd or less [18]. Although the method does not permit the evaluation of acyl lipids or waxes, which are saponified during extraction, it does provide a higher yield of lipids from the bound insoluble fraction of the residue, especially isoprenoid and branched fatty acids [18]. In addition, the method takes approximately half the laboratory preparation time as chloroform/methanol extraction, and often one-third the instrument run-time, as well as producing higher fatty acid yields with less destruction of archaeological samples [18]. For these reasons, acidic methanol extraction is rapidly gaining in popularity in residue studies.

In this study, acidic methanol extraction utilized $2 \% v / v \mathrm{H}_{2} \mathrm{SO}_{4} /$ methanol solution, produced from concentrated $\mathrm{H}_{2} \mathrm{SO}_{4}$ and residue-grade methanol. Five $\mathrm{mL}$ of this solution was added to $2 \mathrm{~g}$ powdered sherd in a glass tube (I). After extraction, the $\mathrm{pH}$ was tested with $\mathrm{pH}$ paper to make sure it was below 4; if it wasn't, more acidic methanol was added, and the extraction was repeated. Although $\mathrm{pH}$ paper is optimized for aqueous solutions, leading to a less accurate reading for a methanol solution than an aqueous one, this reading was sufficient to determine whether the solution remained acidic enough for optimal extraction.

The solvent mixtures were then centrifuged at $2000 \mathrm{rpm}$ for $20 \mathrm{~min}$, the supernatants were transferred to another glass tube (II), and $2 \mathrm{~mL}$ ultrapure water was added. The tubes containing the powdered sherd (I), were additionally extracted with $3 \mathrm{~mL}$ hexane, which was transferred to the tubes containing the corresponding acidic methanol and water mixture (II). After mixing, this hexane was extracted into the final vial. The second culture tubes (II) were then further extracted with $2 \times 2 \mathrm{~mL}$ hexane into the final vials, which were then blown down under $\mathrm{N}_{2}$ gas to dryness.

All pottery was cleaned with a solvent-washed drill bit prior to extraction. All tubes and vials were glass, and all glassware was washed prior to use. All samples were derivatized with approximately $200 \mu \mathrm{L} \mathrm{N}$,O-bis(trimethylsilyl)fluoroacetamide (BSTFA) $+1 \%$ trimethylchlorosilane (TMCS) to produce trimethylsilyl (TMS) esters in the TLE, fatty acid and neutral fractions. The acidic methanol extractions contained methyl esters of fatty acids, produced from the methanol solvent during extraction, and TMS esters of neutral compounds.

Residues were analyzed with a Fisons 8065 gas chromatograph interfaced to a Trio 1000 mass spectrometer, using a DB-1HT $15 \mathrm{~m} \times 0.32 \mathrm{~mm}$ column with $1 \mu \mathrm{L}$ film thickness and with a column head pressure of 7.5 psi. Injection was splitless for $1.0 \mathrm{~min}$, with $2.0 \mu \mathrm{L}$ sample injected into a split/splitless injection port at $250{ }^{\circ} \mathrm{C}$. The helium carrier gas was set at a constant flow of $2.0 \mathrm{~mL} / \mathrm{min}$. The quadrupole mass spectrometer was in electron ionization (EI) mode at $70 \mathrm{eV}$. The MS was in scan mode from 40-600 m/z, with a complete scan lasting $0.517 \mathrm{~s}$. Interface temperature was $250^{\circ} \mathrm{C}$, and source temperature was $240{ }^{\circ} \mathrm{C}$.

Acidic extracted residues and the neutral fraction from the chloroform $/$ methanol extraction were analyzed with the temperature held at $50^{\circ} \mathrm{C}$ for $2 \mathrm{~min}$, and then ramped at $10^{\circ} /$ minute to $325^{\circ} \mathrm{C}$, followed by at $10 \mathrm{~min}$ hold at that temperature. The TLE was analyzed on the same instrument and column, but with a final hold at $350{ }^{\circ} \mathrm{C}$. Fatty acid fractions from the chloroform/methanol extraction were analyzed on the same instrument and column, but the oven temperature was held at $50^{\circ} \mathrm{C}$ for $2 \mathrm{~min}$, ramped from $50^{\circ} \mathrm{C}$ to $150{ }^{\circ} \mathrm{C}$ at $15^{\circ}$ per minute, then $150{ }^{\circ} \mathrm{C}$ to $250^{\circ} \mathrm{C}$ at $3^{\circ}$ per minute, and then held at $250^{\circ} \mathrm{C}$ for $10 \mathrm{~min}$. Procedural solvent blanks were run in parallel with all samples and were used to control for laboratory contamination. All blanks were free of contamination.

Fourteen pottery samples from the George Reeves site (11S650), a multi-component archaeological site dating to the mid-9th and 10th centuries in the Mississippi Valley, were sampled using both chloroform/methanol and acidic methanol extraction, as shown in Figure 1. Twenty $\mu \mathrm{L}$ of $n$-tetratriacontane internal standard were added to the powdered sherds to aid in quantification with both types of extraction. The first four samples (1-4) 
were extracted at different times, with the chloroform/methanol extraction occurring first, and the acidic methanol extraction taking place about 2 years later, with pottery storage at room temperature. This meant that differences between sherd cleaning and the portion of the sherd sampled might lead to different results, as discussed below. The remaining ten samples (5-14) were sampled simultaneously.

Overall lipid yield and yield of individual compounds were calculated in $\mu \mathrm{g}$ lipid/g pottery sherd, in order to allow comparability between chloroform/methanol and acidic extractions, which utilized different sample amounts. Quantification utilized the known amount of the internal standard $n$-tetratriacontane added to all samples, and was calculated according to the formula:

$$
\frac{[\text { Integrated area of peak }(\mathrm{s}) \text { of interest }]}{[\text { Integrated area of internal standard peak }]} *[\text { amt of internal standard }]
$$

The result of this equation was then divided by the amount of sherd sampled to produce lipid yield in $\mu \mathrm{g}$ lipid/g pottery. To obtain overall lipid yield, the integrated areas of all non-contamination components in a residue were totaled and compared to the area of the known amount of internal standard according to the above equation. Overall lipid yield was quantified using the TLE for chloroform/methanol extractions to include acyl lipids when present. Neutral compound quantifications are taken from the saponified neutral fraction of the chloroform/methanol extraction for greater comparability with neutral quantification from the acidic methanol extraction. Because this study focused on neutral compounds, fatty acids were not quantified.

\section{Results}

As expected, overall lipid yield and fatty acid yield were more abundant for acidic methanol extraction than chloroform/methanol extraction despite the smaller sample sizes (Table 1). Isoprenoid fatty acids were detected in four samples extracted by direct acidic extraction, but not in any of the samples extracted by solvent extraction (Samples 9, 10,12, and 14, as shown in Table 1), while all fatty acids were more effectively extracted with the acidic extraction method. This supports the results of the original method description [18].

Overall yield of neutral compounds in $\mu \mathrm{g}$ lipid/g sherd was generally higher for acidic extracted samples than for chloroform/methanol extracted samples, as seen in Table 2. The four samples that were extracted at different times (samples 1-4) appeared to be anomalous. In samples 1, 2, and 4, cholesterol was detected in the chloroform/methanol extractions, but not the acidic extractions. In sample 3, sterol yield in $\mu \mathrm{g}$ lipid/g sherd was comparable for both extraction methods, but cholesterol and sitosterol were detected in the chloroform/methanol extraction, while campesterol and sitosterol were detected in the acidic extraction.

Yield of alkanols for samples 1-4 in $\mu \mathrm{g} / \mathrm{g}$ was comparable in both extraction methods in samples 1 and 3, while for samples 2 and 4, the yield of these compounds was 56-365× larger with solvent extraction than with acidic extraction. Alkane extraction was similarly variable. Yield in $\mu \mathrm{g} / \mathrm{g}$ was comparable for both extraction methods in samples 1 and 2, approximately twice as abundant in the chloroform/methanol extraction of sample 3, and alkanes were absent from the acidic extraction of sample 4, although they were present in the chloroform/methanol extraction of this sample. One of these samples, sample 4, was the only sample in the study with less residue extracted using acidic extraction than by chloroform/methanol extraction. 


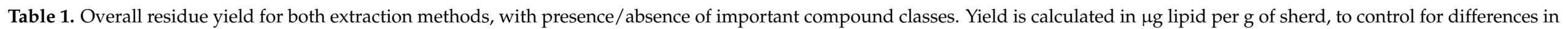

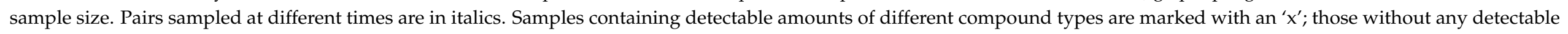

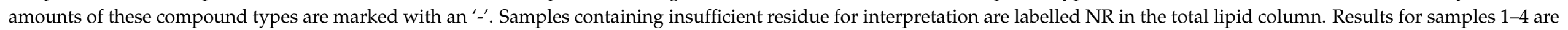
given in italics, as they were not sampled simultaneously.

\begin{tabular}{|c|c|c|c|c|c|c|c|c|c|c|c|c|c|c|c|c|}
\hline \multirow[b]{2}{*}{ No. } & \multicolumn{8}{|c|}{ Chloroform/Methanol Extraction } & \multicolumn{8}{|c|}{ Acidic Methanol Extraction } \\
\hline & $\begin{array}{l}\text { Total } \\
\text { Lipid } \\
\mu \mathrm{g} / \mathrm{g}\end{array}$ & $\begin{array}{c}\text { Sample } \\
\mathrm{g}\end{array}$ & Sterols & $\begin{array}{l}\text { Fatty } \\
\text { Acids }\end{array}$ & $\begin{array}{c}\text { Isoprenoid } \\
\text { FA }\end{array}$ & Alkanols & Alkanes & Terpenoids & $\begin{array}{c}\text { Total } \\
\text { Lipid } \\
\mu \mathrm{g} / \mathrm{g}\end{array}$ & $\begin{array}{c}\text { Sample } \\
\mathrm{g}\end{array}$ & Sterols & $\begin{array}{l}\text { Fatty } \\
\text { Acids }\end{array}$ & $\begin{array}{c}\text { Isoprenoid } \\
\text { FA }\end{array}$ & Alkanols & Alkanes & Terpenoids \\
\hline 1 & 8.2 & 9.1 & $x$ & $x$ & - & $x$ & $x$ & - & 17.6 & 2.6 & - & $x$ & - & $x$ & $x$ & $x$ \\
\hline 2 & 8.9 & 12.5 & $x$ & $x$ & - & $x$ & $x$ & $x$ & 12.7 & 2.2 & - & $x$ & - & $x$ & $x$ & - \\
\hline 3 & 8.9 & 7.8 & $x$ & $x$ & - & $x$ & $x$ & $x$ & 33.7 & 2.5 & - & $x$ & - & - & $x$ & $x$ \\
\hline 4 & 3.2 & 11.5 & $x$ & $x$ & - & - & - & - & $0.5 \mathrm{NR}$ & 2.4 & - & $x$ & - & - & - & $x$ \\
\hline 5 & $0.6 \mathrm{NR}$ & 7.9 & - & $x$ & - & $x$ & $x$ & $x$ & 5.9 & 2.3 & $x$ & $x$ & - & - & $x$ & - \\
\hline 7 & 30.9 & 5.1 & $x$ & $x$ & - & $x$ & $x$ & $x$ & 3186.5 & 2.3 & $x$ & $x$ & - & $x$ & $x$ & $x$ \\
\hline 8 & 105.7 & 5.1 & $x$ & $x$ & - & $x$ & $x$ & - & 1842.7 & 2.4 & $x$ & $x$ & - & $x$ & $x$ & $x$ \\
\hline 9 & $1.8 \mathrm{NR}$ & 10.9 & $x$ & $x$ & - & $x$ & $x$ & - & 69.9 & 2.7 & - & $x$ & $x$ & $x$ & $x$ & - \\
\hline 10 & $0.4 \mathrm{NR}$ & 3.9 & - & $x$ & - & $x$ & $x$ & - & 103.0 & 2.0 & - & $x$ & $x$ & $x$ & $x$ & - \\
\hline 11 & $0.7 \mathrm{NR}$ & 5.3 & - & $x$ & - & - & - & - & 37.6 & 2.3 & $x$ & $x$ & - & $x$ & $x$ & $x$ \\
\hline 12 & 4.2 & 4.7 & $x$ & $x$ & - & $x$ & $x$ & - & 83.8 & 2.1 & $x$ & $x$ & $x$ & $x$ & $x$ & $x$ \\
\hline 13 & 2.0 & 4.8 & $x$ & $x$ & - & $x$ & $x$ & - & 70.5 & 2.5 & $x$ & $x$ & - & $x$ & $x$ & - \\
\hline 14 & 97.0 & 2.8 & - & $x$ & - & - & - & - & 871.0 & 2.4 & - & $x$ & $x$ & - & - & - \\
\hline
\end{tabular}




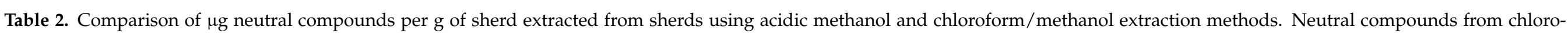

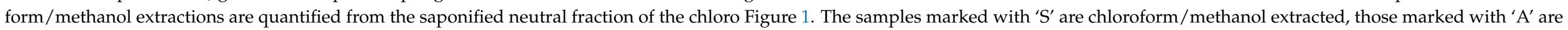

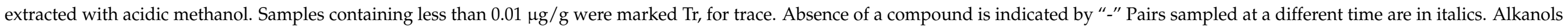

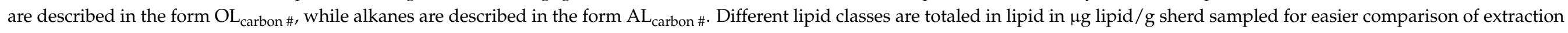
methods. Results for samples 1-4 are given in italics, as they were not sampled simultaneously.

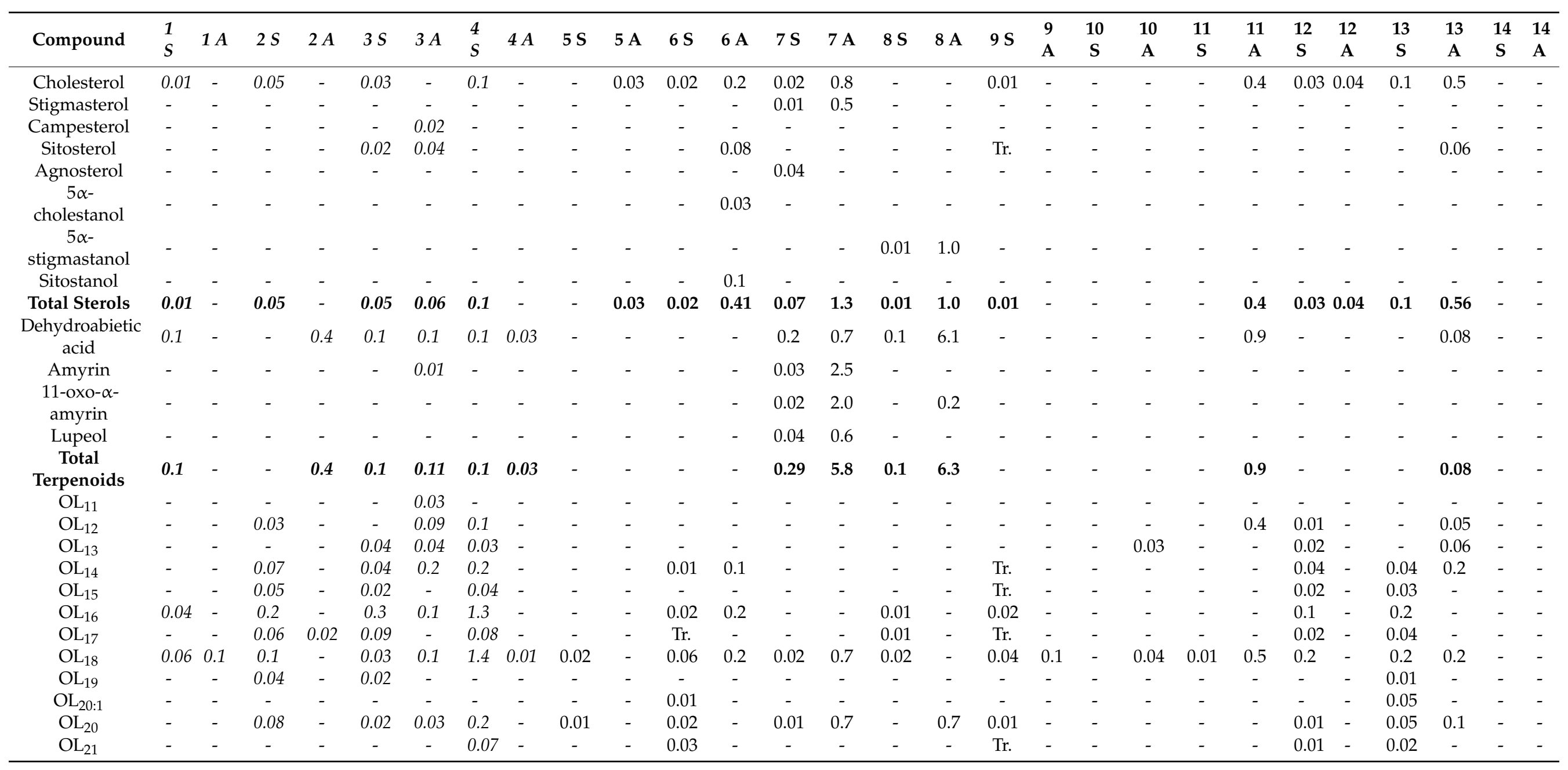


Table 2. Cont.

\begin{tabular}{|c|c|c|c|c|c|c|c|c|c|c|c|c|c|c|c|c|c|c|c|c|c|c|c|c|c|c|c|c|}
\hline Compound & $\begin{array}{l}1 \\
S\end{array}$ & $1 A$ & $2 S$ & $2 A$ & $3 S$ & $3 A$ & $\begin{array}{l}4 \\
S\end{array}$ & $4 A$ & $5 \mathrm{~S}$ & $5 \mathrm{~A}$ & $6 \mathrm{~S}$ & $6 \mathrm{~A}$ & $7 \mathrm{~S}$ & $7 \mathrm{~A}$ & $8 \mathrm{~S}$ & $8 \mathrm{~A}$ & $9 \mathrm{~S}$ & $\begin{array}{l}9 \\
\mathrm{~A}\end{array}$ & $\begin{array}{c}10 \\
S\end{array}$ & $\begin{array}{l}10 \\
\mathrm{~A}\end{array}$ & $\begin{array}{l}11 \\
S\end{array}$ & $\begin{array}{l}11 \\
\text { A }\end{array}$ & $\begin{array}{l}12 \\
S\end{array}$ & $\begin{array}{l}12 \\
\text { A }\end{array}$ & $\begin{array}{c}13 \\
S\end{array}$ & $\begin{array}{l}13 \\
\mathrm{~A}\end{array}$ & $\begin{array}{l}14 \\
S\end{array}$ & $\begin{array}{l}14 \\
\mathrm{~A}\end{array}$ \\
\hline $\mathrm{OL}_{22}$ & - & - & 0.2 & - & 0.03 & 0.02 & 0.1 & - & 0.01 & - & - & - & - & 0.2 & 0.02 & 0.2 & Tr. & - & - & 0.06 & - & - & Tr. & - & 0.03 & 0.07 & - & - \\
\hline $\mathrm{OL}_{23}$ & - & - & - & - & 0.01 & - & 0.04 & - & - & - & - & - & - & - & - & 0.1 & Tr. & - & - & - & - & - & - & - & 0.01 & 0.03 & - & - \\
\hline $\mathrm{OL}_{25}$ & - & - & - & - & - & - & - & - & - & - & - & - & - & 0.07 & - & 0.1 & - & - & - & 0.03 & - & - & - & - & - & - & - & - \\
\hline $\mathrm{OL}_{26}$ & - & - & 0.06 & - & - & - & 0.03 & - & 0.3 & - & 0.01 & 0.1 & 0.01 & 1.0 & 0.05 & 0.7 & $\mathrm{Tr}$ & - & 0.04 & 0.4 & - & - & 0.01 & - & - & - & - & - \\
\hline $\mathrm{OL}_{27}$ & - & - & - & - & - & - & - & - & - & - & - & - & - & 0.07 & - & - & - & - & - & 0.03 & - & - & - & - & - & - & - & - \\
\hline $\mathrm{OL}_{28}$ & - & - & 0.1 & - & 0.03 & 0.03 & - & - & 0.05 & - & 0.08 & 0.7 & 0.07 & 7.2 & 0.07 & 0.9 & Tr. & - & 0.04 & 0.5 & - & - & 0.02 & - & 0.02 & - & - & - \\
\hline $\mathrm{OL}_{30}$ & 0.01 & - & 0.05 & - & 0.03 & 0.03 & - & - & 0.04 & - & 0.07 & 0.5 & 0.1 & 4.1 & 0.07 & 0.9 & Tr. & - & 0.09 & 0.9 & - & - & 0.01 & - & 0.01 & - & 0.02 & - \\
\hline $\mathrm{OL}_{31}$ & - & - & - & - & - & - & - & - & - & - & - & - & - & - & - & - & - & - & - & 0.1 & - & - & - & - & - & - & - & - \\
\hline $\mathrm{OL}_{32}$ & - & - & - & - & - & - & - & - & - & - & - & 0.06 & - & 0.5 & 0.04 & 1.0 & - & - & 0.3 & 4.2 & - & - & - & - & - & - & - & - \\
\hline $\mathrm{OL}_{33}$ & - & - & - & - & - & - & - & - & - & - & - & - & - & - & - & - & - & - & - & 0.3 & - & - & - & - & - & - & - & - \\
\hline $\mathrm{OL}_{34}$ & - & - & - & - & - & - & - & - & - & - & - & - & - & 0.6 & - & - & - & - & 0.08 & 4.4 & - & - & - & - & - & - & - & - \\
\hline $\begin{array}{c}\text { Total } \\
\text { Alkanols }\end{array}$ & 0.11 & 0.1 & 1.12 & 0.02 & 0.67 & 0.67 & 3.65 & 0.01 & 0.46 & - & 0.33 & 1.78 & 0.22 & 14.4 & 0.35 & 5.2 & 0.07 & 0.1 & 1.31 & 11.4 & 0.01 & 0.9 & 0.48 & - & 0.74 & 0.71 & 0.02 & - \\
\hline $\mathrm{AL}_{14}$ & - & - & - & - & - & - & - & - & - & - & - & - & - & - & - & - & - & - & - & - & - & - & 0.01 & 0.09 & - & - & - & 0.4 \\
\hline $\mathrm{AL}_{15}$ & - & - & - & - & - & 0.08 & - & - & - & - & - & - & - & - & - & - & - & - & - & - & - & - & 0.02 & 0.03 & 0.01 & - & - & - \\
\hline $\mathrm{AL}_{17}$ & - & - & - & - & - & 0.09 & - & - & - & - & - & - & - & - & - & - & - & - & - & 0.04 & - & - & 0.06 & 0.4 & 0.02 & 0.04 & - & - \\
\hline $\mathrm{AL}_{18: 1}$ & - & - & - & - & - & - & - & - & - & - & - & - & - & - & - & - & - & - & - & - & - & - & - & - & - & 0.4 & - & - \\
\hline $\mathrm{AL}_{18}$ & 0.03 & - & 0.08 & - & 0.06 & 0.07 & - & - & - & - & - & - & - & - & - & - & - & - & - & 0.08 & - & 0.6 & 0.04 & 0.2 & 0.04 & 0.3 & - & - \\
\hline $\mathrm{AL}_{19: 1}$ & - & - & - & - & 0.1 & - & - & - & - & - & - & - & - & - & - & - & - & 0.2 & - & - & - & - & - & - & - & - & - & - \\
\hline $\mathrm{AL}_{19}$ & 0.04 & - & 0.2 & - & 0.07 & - & - & - & - & - & - & - & - & - & - & - & - & - & - & - & - & - & 0.02 & - & 0.07 & 0.1 & - & - \\
\hline $\mathrm{AL}_{20: 1}$ & - & - & - & - & - & - & - & - & - & - & - & - & - & - & - & - & - & - & - & - & - & - & - & - & 0.04 & - & - & - \\
\hline $\mathrm{AL}_{20}$ & 0.04 & 0.08 & 0.1 & - & 0.1 & 0.07 & 0.1 & - & - & - & 0.01 & - & - & - & 0.01 & - & 0.01 & 0.3 & - & - & - & 0.7 & 0.05 & - & 0.09 & 0.2 & - & - \\
\hline $\mathrm{AL}_{21: 1}$ & - & - & 0.1 & - & 0.2 & - & - & - & - & - & Tr. & - & - & - & - & - & - & 0.3 & - & - & - & - & - & - & - & - & - & - \\
\hline $\mathrm{AL}_{21}$ & - & 0.2 & 0.06 & - & 0.1 & - & 0.03 & - & - & - & - & - & - & - & - & - & 0.01 & - & - & - & - & - & 0.03 & - & 0.03 & - & - & - \\
\hline $\mathrm{AL}_{22}$ & 0.04 & - & 0.1 & 0.2 & 0.09 & - & - & - & 0.02 & 0.06 & 0.02 & - & - & - & - & - & 0.01 & - & - & 0.2 & - & - & - & 0.06 & 0.02 & - & - & - \\
\hline $\mathrm{AL}_{23: 1}$ & - & - & 0.08 & - & - & - & - & - & - & - & - & - & - & - & - & - & - & - & - & - & - & - & - & - & - & - & - & 4.0 \\
\hline $\mathrm{AL}_{23}$ & 0.02 & - & 0.05 & 0.07 & 0.04 & 0.2 & 0.05 & - & - & 0.05 & - & - & - & - & 0.02 & - & Tr. & 0.1 & - & 0.3 & - & 0.3 & Tr. & 0.08 & Tr. & - & - & - \\
\hline $\mathrm{AL}_{24}$ & 0.03 & 0.1 & 0.1 & 0.4 & 0.06 & 0.09 & 0.2 & - & - & 0.05 & 0.01 & - & - & - & - & - & Tr. & - & - & 0.1 & - & - & - & 0.2 & - & 0.06 & - & - \\
\hline $\mathrm{AL}_{25}$ & 0.05 & 0.1 & - & 0.2 & 0.04 & 0.04 & 0.09 & - & - & 0.06 & - & - & - & - & 0.01 & - & - & - & - & 0.07 & - & - & - & 0.07 & 0.01 & 0.2 & - & - \\
\hline $\mathrm{AL}_{26}$ & 0.07 & 0.1 & 0.05 & 0.2 & 0.08 & 0.01 & 0.1 & - & - & 0.03 & - & - & - & - & - & - & - & 0.1 & - & 0.06 & - & - & - & 0.08 & - & 0.2 & - & 0.1 \\
\hline $\mathrm{AL}_{27}$ & 0.09 & 0.08 & 0.1 & 0.2 & 0.09 & - & 0.1 & - & - & 0.03 & - & - & - & - & - & - & - & - & - & 0.1 & - & 0.1 & 0.01 & 0.04 & 0.02 & 0.04 & - & 0.2 \\
\hline $\mathrm{AL}_{28}$ & 0.1 & 0.07 & 0.08 & 0.08 & 0.1 & - & 0.08 & - & - & - & - & - & - & - & - & - & - & - & - & 0.05 & - & - & - & - & - & - & - & - \\
\hline
\end{tabular}


Table 2. Cont.

\begin{tabular}{|c|c|c|c|c|c|c|c|c|c|c|c|c|c|c|c|c|c|c|c|c|c|c|c|c|c|c|c|c|}
\hline Compound & $\begin{array}{l}1 \\
S\end{array}$ & $1 A$ & $2 S$ & $2 A$ & $3 S$ & $3 A$ & $\begin{array}{l}4 \\
S\end{array}$ & $4 A$ & $5 \mathrm{~S}$ & $5 \mathrm{~A}$ & $6 S$ & $6 \mathrm{~A}$ & $7 \mathrm{~S}$ & $7 \mathrm{~A}$ & $8 \mathrm{~S}$ & $8 \mathrm{~A}$ & $9 S$ & $\begin{array}{l}9 \\
\mathrm{~A}\end{array}$ & $\begin{array}{c}10 \\
\text { S }\end{array}$ & $\begin{array}{l}10 \\
\text { A }\end{array}$ & $\begin{array}{c}11 \\
S\end{array}$ & $\begin{array}{l}11 \\
\text { A }\end{array}$ & $\begin{array}{l}12 \\
S\end{array}$ & $\begin{array}{l}12 \\
\mathrm{~A}\end{array}$ & $\begin{array}{c}13 \\
S\end{array}$ & $\begin{array}{l}13 \\
\mathrm{~A}\end{array}$ & $\begin{array}{l}14 \\
\text { S }\end{array}$ & $\begin{array}{l}14 \\
\text { A }\end{array}$ \\
\hline $\mathrm{AL}_{29}$ & 0.1 & - & 0.1 & - & 0.09 & - & 0.08 & - & 0.04 & - & - & - & 0.01 & - & 0.01 & - & Tr. & - & 0.03 & 0.3 & - & 0.5 & 0.03 & 0.09 & 0.04 & 0.4 & - & 0.1 \\
\hline $\mathrm{AL}_{30}$ & 0.05 & - & 0.05 & 0.04 & 0.04 & - & 0.04 & - & - & - & - & - & - & 0.1 & - & 0.08 & - & - & - & 0.04 & - & - & - & - & 0.01 & - & - & - \\
\hline $\mathrm{AL}_{31}$ & 0.06 & - & 0.06 & 0.08 & 0.07 & - & 0.04 & - & 0.01 & - & 0.02 & - & 0.02 & - & 0.01 & - & Tr. & 0.05 & 0.06 & 0.3 & - & 0.3 & 0.03 & 0.05 & 0.03 & 0.3 & - & - \\
\hline $\mathrm{AL}_{32}$ & 0.02 & - & 0.02 & 0.08 & 0.04 & 0.04 & 0.03 & - & 0.01 & - & 0.01 & - & 0.01 & - & 0.01 & - & Tr. & 0.06 & 0.01 & 0.1 & - & 0.2 & 0.01 & 0.05 & 0.01 & 0.3 & - & - \\
\hline $\mathrm{AL}_{33}$ & 0.02 & - & 0.02 & - & 0.04 & - & 0.03 & - & 0.01 & - & 0.01 & - & Tr. & - & Tr. & - & Tr. & 0.05 & 0.01 & 0.07 & - & - & 0.01 & 0.07 & 0.01 & - & 0.01 & - \\
\hline $\mathrm{AL}_{35}$ & - & - & - & - & - & - & - & - & - & - & 0.01 & - & - & - & - & - & Tr. & 0.08 & - & - & - & - & - & 0.05 & - & 0.08 & - & - \\
\hline Total Alkanes & 0.076 & 60.073 & 1.35 & 1.55 & 1.41 & 0.79 & 0.97 & - & 0.09 & 0.28 & 0.09 & - & 0.04 & 0.3 & 0.07 & 0.08 & 0.03 & 1.24 & 0.11 & 1.81 & - & 2.7 & 0.35 & 1.76 & 0.47 & 2.65 & 0.01 & 4.8 \\
\hline
\end{tabular}


This pattern was not present in the sherds that were sampled simultaneously (samples 5-14), as seen in Tables 1-3, in which sterols and alkanes were extracted more completely by the acidic extraction. The difference between simultaneously and non-simultaneously sampled residues may be caused by variation in the location of the sherd sampled in the non-simultaneous samples. The optimal portion of the sherd may have been selected in the initial sampling event, the chloroform/methanol extraction, leaving a more residue-poor portion of the sherd for later acidic methanol extraction. Alternatively, preservation issues and breakdown of compounds within the pottery may have caused the loss of sterols during the 2-year storage period at room temperature between the chloroform/methanol extraction and the acidic methanol extraction. Because of the clear difference between simultaneous and non-simultaneous extraction, residues extracted non-simultaneously are marked by italics within Tables 1 and 2, and are reported separately in Table 3.

Table 3. Overall success of extraction methods for different compound classes in the study for all samples. Extractions that are more complete either contained compounds that were not present in the other extraction method, or contained more than $1.5 \times$ more of a compound class than the other, measured in $\mu \mathrm{g}$ lipid/g sherd. Comparable extractions were those in which the compound class was absent in both extractions, or in which the compound class was within $1.5 \times$ of each other in both extractions, measured in $\mu \mathrm{g}$ lipid/g sherd.

\begin{tabular}{cccc}
\hline & $\begin{array}{c}\text { Chloroform/Methanol } \\
\text { Extraction More } \\
\text { Complete }\end{array}$ & Comparable & $\begin{array}{c}\text { Acidic Methanol } \\
\text { Extraction More } \\
\text { Complete }\end{array}$ \\
\hline Samples 1-4 Sterols & 3 & 1 & 0 \\
Samples 1-4 Terpenoids & 2 & 1 & 1 \\
Samples 1-4 Alkanols & 2 & 2 & 0 \\
Samples 1-4 Alkanes & 2 & 1 & 1 \\
Samples 1-4 Totals & $\mathbf{9}$ & $\mathbf{5}$ & $\mathbf{1}$ \\
Samples 5-14 Sterols & 1 & 3 & 6 \\
Samples 5-14 Terpenoids & 0 & 6 & 5 \\
Samples 5-14 Alkanols & 3 & 1 & 8 \\
Samples 5-14 Alkanes & 1 & $\mathbf{1 1}$ & $\mathbf{2 4}$ \\
Samples 5-14 Totals & $\mathbf{5}$ & $\mathbf{1 6}$ & $\mathbf{2 5}$ \\
All Samples Totals & $\mathbf{1 4}$ & & \\
\hline
\end{tabular}

\subsection{Sterol and Terpenoid Extractions}

As described above and shown in Tables 2 and 3, acidic methanol extraction removed greater or comparable abundances of $\mu \mathrm{g}$ sterols/gram of sherd than chloroform/methanol extraction for all simultaneously sampled sherds except sample 9. This was an unusual residue, in which the chloroform/methanol extract contained very few fatty acids, but small amounts of a wide range of neutral compounds, as seen in Table 2. The acidic extraction, conversely, contained abundant fatty acids and a narrower range of neutral compounds, especially alkanols. It is worth noting that the chloroform/methanol extraction from this sherd contained so few lipids that it would be considered uninterpretable, as shown in Table 1, and so its results are not particularly reliable.

In all other simultaneous extractions, sterols were more completely extracted using the acidic extraction method, or extraction was comparable between the two methods. In samples 5 and 11, cholesterol was detectable in the acidic extraction, but not in the chloroform/methanol extraction. Samples 10,12, and 14 had broadly comparable extraction of sterols using both methods. No sterols were detectable with either method in samples 10 and 14, while sample 12 contained comparable amounts of cholesterol using both methods (total sterols for the two extractions within $1.5 \times$ of each other). Sterols in samples $6,7,8$, and 13 were extracted more successfully using the acidic extraction method, with yields ranging from 5 to $100 \times$ more $\mu \mathrm{g}$ sterols/gram of sherd in the acidic extraction than the chloroform/methanol extraction. 
Four terpenoids were commonly extracted from sherds in this study: the triterpenoids amyrin, 11-oxo- $\alpha$-amyrin and lupeol, and the diterpenoid dehydroabietic acid. The acidic extraction was most effective or comparable to chloroform/methanol extraction of these compounds, as seen in Table 3. No terpenoids were extracted using either method in samples $5,6,9,10,12$ or 14 . The diterpenoid dehydroabietic acid was detectable using acidic extraction in samples 11 and 13, but not using chloroform/methanol extraction. Terpenoids were detected using both extraction methods in samples 7 and 8, but with noticeably more terpenoids extracted using acidic extraction, with terpenoid yields per gram of sherd $20 \times$ greater with the acidic extraction for sample 7 and $63 \times$ greater for sample 8 .

\subsection{Alkanol Extraction}

There was some interesting variation in the extraction of alkanols between the two techniques. Excluding the non-simultaneous extractions, alkanols were extracted more effectively with the acidic methanol extraction from samples $6,7,8,10$, and 11, ranging from $5 \times$ (sample 6) more alkanols $/ g$ of sherd using acidic extraction to $90 \times$ more (sample 11). Alkanols were extracted more effectively with the chloroform/methanol extraction from samples 5, 12, and 14. In these three samples, alkanols were detected in the chloroform/methanol extraction, but were completely absent from the acidic extraction. Few alkanols were extracted using either method from 14, although more were removed from the ceramic using chloroform/methanol extraction. Both extraction methods had comparable results for alkanol extraction for samples 13 and 9. On the whole, as shown in Table 3, alkanols were extracted more successfully or comparably to solvent extraction in 7 out of 10 of the simultaneous samples, and 9 out of 14 in all samples. In this small study, although acidic extraction appeared more successful in extracting alkanols, neither extraction technique was clearly superior.

\subsection{Alkane Extraction}

Extraction of alkanes from residues was usually more successful using acidic extraction. Acidic extraction was more effective in removing alkanes from pottery for samples 5 , $7,9,10,11,12,13$, and 14 . In some cases, the improved extraction of alkanes using the acidic method was dramatic, with alkane yields ranging from $5 \times($ sample 13$)$ to $480 \times$ (sample 14), greater with the acidic extraction compared to the chloroform/methanol extraction, measured by total $\mu \mathrm{g}$ alkanes/g sampled sherd. Alkanes were extracted at comparable levels for sample 8. Chloroform/methanol extraction was more effective in removing alkanes only from sample 6, which contained a small amount of these compounds, as shown in Table 2.

\section{Discussion}

Variation was present within the overall effectiveness of the acidic extraction protocol within different compound types, especially alkanols. There was no compound type, however, in which chloroform/methanol extraction was consistently more effective than acidic methanol extraction.

Acidic methanol extraction was, as has been previously published, clearly superior in extracting fatty acids from the bound insoluble fraction. Aside from the non-simultaneous extractions, there was only one case in this study (sample 6, discussed below) where the interpretation of a residue was less detailed for the acidic methanol extraction than for the chloroform/methanol extraction. There were seven sherds in which the interpretation of residues was noticeably improved in specificity and confidence using acidic extraction. Two of the simultaneously sampled residues, 7 and 8 , had similar or identical interpretations using both extraction methods.

Four samples that contained insufficient residue for interpretation with the solvent extraction did contain interpretable residue with the acidic methanol extraction, as shown in Table 1 (samples 5,9,10, and 11). Of these four, sample 5 contained a small amount 
of residue using both extraction methods. Sample 10 is discussed in more detail below. Three samples, 12, 13, and 14, had more detailed interpretations using the acidic methanol extraction, because of the addition of new compounds extracted using the acidic methanol.

Sample 12 was tentatively identified as containing fish from the chloroform/methanol extraction, based on the presence of cholesterol and a low ratio of $C_{18: 0} / C_{16: 0}$ fatty acids. This tentative identification was confirmed by the extraction of isoprenoid fatty acids using acidic methanol extraction. Isopimaric acid, a diterpenoid, was also extracted using acidic methanol, but was not extracted using chloroform/methanol, adding the confirmed presence of conifer resin to the interpretation of that residue.

Sample 13 was also tentatively identified as containing fish based on cholesterol and a low ratio of $\mathrm{C}_{18: 0} / \mathrm{C}_{16: 0}$ fatty acids in the chloroform/methanol extraction. Interestingly, this tentative identification was not confirmed from the acidic methanol extraction, which did not contain isoprenoid fatty acids or other indicators of the presence of fish or shellfish. The acidic methanol extraction of this sherd did extract plant sterol and diterpenoids that were not extracted with chloroform/methanol, leading to a more detailed and notably shifted interpretation, using acidic extraction as opposed to chloroform/methanol extraction.

Sample 14 was an abundant, but indeterminate and undiagnostic residue using both extraction methods; however, the acidic methanol did extract isoprenoid fatty acids and ketones, biomarkers for exposure to high heat, that were not present in the chloroform/methanol extraction. This sherd was therefore difficult to interpret using both methods, but the acidic methanol extraction allowed the identification of both fish/shellfish and high heat.

Sample 6 was unusual, in that the acidic methanol extraction recovered sitosterol that was not extracted using chloroform/methanol, permitting the positive identification of plant resources in the residue. The chloroform/methanol extraction, however, recovered dehydroabietic acid, a diterpenoid, that was not found in the acidic methanol extraction. As a result, the interpretation of this sample was less detailed using the acidic methanol extraction than with the chloroform/methanol extraction; both methods identified plants, but the chloroform/methanol extraction identified at least one type of plant present in the residue. Sample 6 was the only residue in the study in which this was the case.

In general, shifts in the overall interpretation of residues was due to the apparent increased extraction of interpretively important compounds using the acidic methanol extraction. Shifts in relative amounts of different compounds that lead to changes in interpretation did not occur in this study.

An interesting and demonstrative pattern can be seen in sample 10. The chloroform/methanol extraction removed very small amounts of residue from the sherd $(0.4 \mu \mathrm{g}$ $\mathrm{lipid} / \mathrm{g}$ sherd), which was distinctive in that it contained larger-than-usual amounts of long-chain alkanols, notably $n$-dotriacontanol $\left(\mathrm{OL}_{32}\right)$ and $n$-tetratriacontanol $\left(\mathrm{OL}_{34}\right)$, shown in Figure 2. The acidic extraction recovered large amounts (103 $\mu \mathrm{g}$ lipid/g sherd) of similarly distinctive residue, presumably from the bound insoluble portion of the residue (Figure 3). Both $\mathrm{OL}_{32}$ and $\mathrm{OL}_{34}$ are unusual, and $\mathrm{OL}_{32}$ can be used as an isotopic biomarker for the presence of maize in residues [19]. 
I.S.

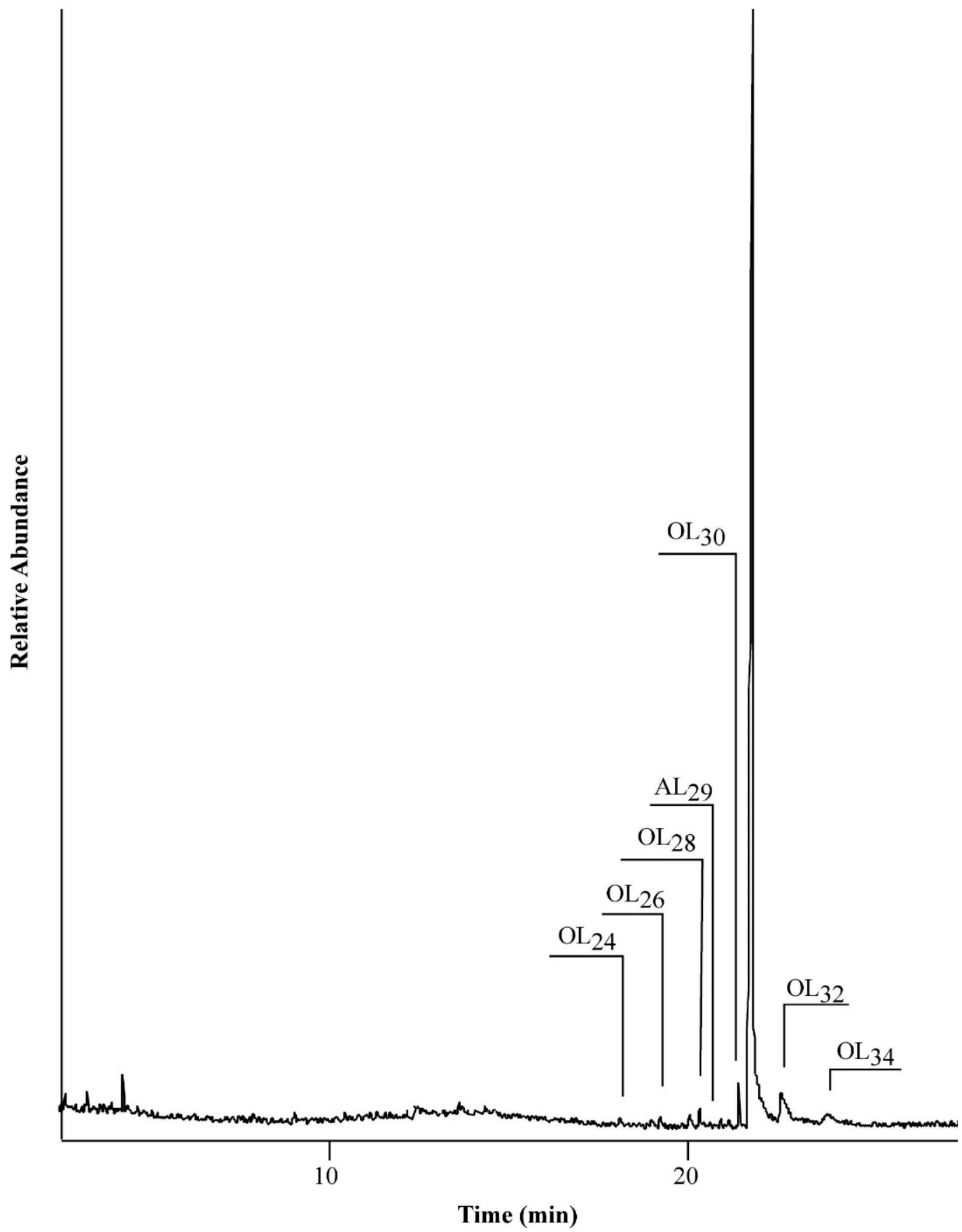

Figure 2. GC/MS of neutral fraction from chloroform/methanol extraction of sample 10. Note that the long-chain alkanol series is present, but in smaller amounts than the acidic methanol extraction, shown in Figure 3. 


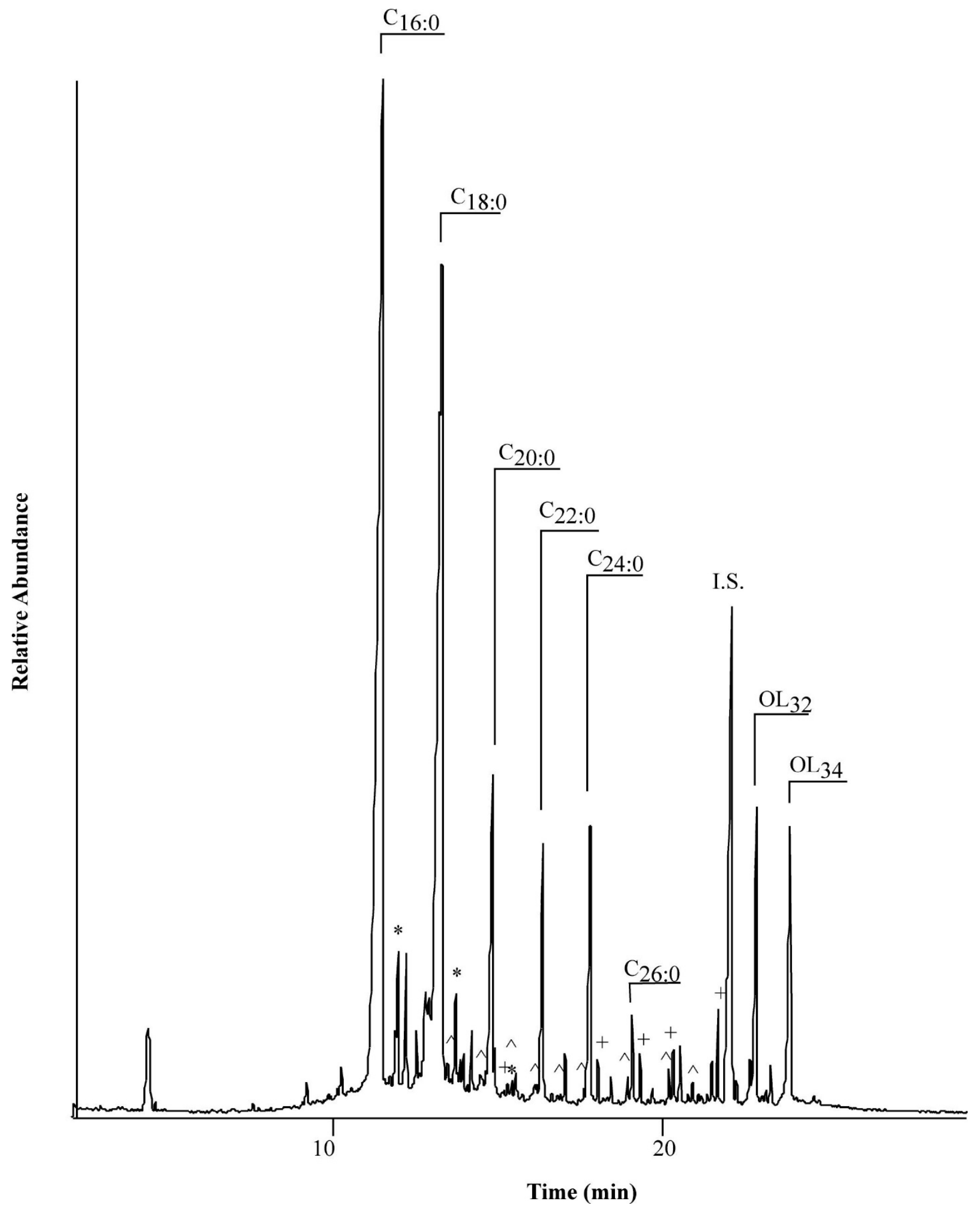

Figure 3. GC/MS of acidic methanol extraction from sample 10. Isoprenoid fatty acids are marked by *, alkanols by + , and alkanes by ${ }^{\wedge}$. Note the unusually abundant long-chain alkanols $\mathrm{OL}_{32}$ and $\mathrm{OL}_{34}$.

The amount of total lipid quantified from the solvent extraction was insufficient for reliable interpretation (NR), as can be seen in Table 1. Using the solvent extraction, the alkanols present were interesting, but could not be interpreted due to the small amount of lipid present. Acidic extraction, however, produced the same alkanol profile as the solvent 
extraction, as shown in Figures 2 and 3, but with sufficient residue for interpretation. Using acidic extraction, this residue could be interpreted, and could also undergo compoundspecific isotope analysis, which is discussed in greater detail elsewhere [28].

In addition, the acidic extraction of sample 10 contained three isoprenoid fatty acids (pristanic, phytanic, and TMTD), as shown in Figure 3, and a series of saturated fatty acids from $\mathrm{C}_{14}$ to $\mathrm{C}_{28}$ that were not present in the chloroform/methanol extraction, as well as the monounsaturated fatty acid $\mathrm{C}_{24: 1}$. The fatty acid fraction from the chloroform/methanol extraction of sample 10 was comprised only of $C_{16: 0}$ and $C_{18: 0}$. Residue interpretation of this sample was therefore greatly enhanced by the use of acidic extraction.

This preliminary comparison of extraction methods suggests that acidic extraction of pottery residues usually provides greater yields of both neutral compounds and fatty acids than chloroform/methanol extraction. Acidic extraction, as described elsewhere, requires smaller sample sizes, and provides better extraction of fatty acids, quicker lab processing and less lab throughput time. Because of these advantages, when compound classes are extracted at comparable levels using each method, acidic extraction is preferred. Table 3 summarizes overall extraction yields using both methods. In all samples, including the problematic non-simultaneously sampled group, acidic extraction released more neutral compounds from the ceramic matrix in 25 of 56 cases, and extracted comparable amounts of the neutral compounds in 16 of 56 cases. In 41 of 56 cases (73\%), therefore, acidic extraction provided equivalent or better extraction of neutral compounds than chloroform/methanol extraction.

The results of this study suggest that many neutral compounds, similar to fatty acids, may be retained within the ceramic matrix as part of the bound insoluble fraction, at least in chloroform/methanol extraction. This study did not attempt to elucidate the ways in which these compounds might bind within the ceramic, nor did it attempt to determine whether additional neutral compounds might be retained within the ceramic following acidic extraction. Further studies should address these interesting questions.

Among the neutral compounds evaluated in this study, sterols, terpenoids, and alkanes were extracted from the ceramic matrix more effectively using the acidic extraction method, or were extracted comparably by both methods. Alkanols were extracted optimally or comparably by acidic extraction more than half the time (9 of 14). Given the overall effectiveness of the extraction of fatty acids, sterols, terpenoids, and alkanes as well as lipids overall, this preliminary study suggests that acidic methanol extraction is optimal for most residue applications that do not require the evaluation of acyl lipids, including those focusing on plant processing in pottery vessels [18].

Further studies, using a wider range of ceramics from a wider geographic and temporal range, will be needed to determine the optimal extraction method for neutral compounds with more certainty. Having said this, it has already been established that acidic methanol extraction is more successful at removing fatty acids from ceramic matrix than chloroform/methanol extraction across a range of different pottery types, firing methods, and geographic regions [18]. It therefore seems plausible that this advantage would also be present in the removal of at least some categories of neutral compounds.

Given the advantages of acidic extraction, this study therefore suggests that acidic methanol extraction can be used as a primary screening and interpretive step in projects focusing on plant processing. Secondary chloroform/methanol extractions can be reserved for evaluating acyl lipids, and possibly in cases where alkanol extraction is essential to the research question.

Funding: This research received no external funding.

Institutional Review Board Statement: Not applicable.

Informed Consent Statement: Not applicable.

Data Availability Statement: The data presented in this study are available on request from the corresponding author. The data are not publicly available due to university security procedures. 
Acknowledgments: The author gratefully acknowledges John E. Kelly for permitting the repeated destructive analysis of ceramics from 11S650. Elizabeth Boswell assisted in sample preparation, and Mike Elefante maintained laboratory instrumentation at the UNCW Residue Lab. Two anonymous reviewers' comments on a previous version of the paper were materially helpful in this, hopefully improved, version. All mistakes are the responsibility of the author.

Conflicts of Interest: The author declares no conflict of interest.

\section{References}

1. Copley, M.S.; Berstan, R.; Dudd, S.N.; Docherty, G.; Mukherjee, A.J.; Straker, V.; Payne, S.; Evershed, R.P. Direct chemical evidence for widespread dairying in prehistoric Britain. Proc. Natl. Acad. Sci. USA 2003, 100, 1524-1529.

2. Craig, O.E.; Forster, M.; Andersen, S.H.; Koch, E.; Crombé, P.; Milner, N.J.; Stern, B.; Bailey, G.N.; Heron, C.P. Molecular and isotopic demonstration of the processing of aquatic products in northern European prehistoric pottery. Archaeometry 2007, 49, 135-152. [CrossRef]

3. Craig, O.E.; Shillito, L.; Albarella, U.; Viner-Daniels, S.; Chan, B.; Cleal, R.; Ixer, R.; Jay, M.; Marshall, P.; Simmons, E.; et al. Feeding Stonehenge: Cuisine and consumption at the late Neolithic site of Durrington Walls. Antiquity 2015, 89, 1096-1109. [CrossRef]

4. Dudd, S.N.; Evershed, R.P.; Gibson, A.M. Evidence for Varying Patterns of Exploitation of Animal Products in Different Prehistoric Pottery Traditions Based on Lipids Preserved in Surface and Absorbed Residues. J. Archaeol. Sci. 1999, 26, 1473-1482. [CrossRef]

5. Eerkens, J. The preservation and identification of piñon resins by GC-MS in pottery from the Western Great Basin. Archaeometry 2002, 44, 95-105.

6. Evershed, R.P. Organic residue analysis in archaeology: The archaeological biomarker revolution. Archaeometry 2008, 50, 895-924.

7. Evershed, R.P.; Heron, C.; Goad, L.J. Analysis of organic residues of archaeological origin by high-temperature gas chromatography and gas chromatography-mass spectrometry. Analyst 1990, 115, 1339-1342. [CrossRef]

8. Evershed, R.P.; Mottram, H.R.; Dudd, S.N.; Charters, S.; Stott, A.W.; Lawrence, G.J.; Gibson, A.M.; Conner, A.; Blinkhorn, P.W.; Reeves, V. New criteria for the identification of animal fats preserved in archaeological pottery. Naturwissenschaften 1997, 84, 402-406. [CrossRef]

9. Heron, C.; Evershed, R.P. The analysis of organic residues and the study of pottery use. In Archaeological Method and Theory; Schiffer, M.B., Ed.; University of Oregon Press: Tucson, OR, USA, 1990; Volume 5, pp. 247-284.

10. Malainey, M.E.; Przbylski, R.; Sherriff, B.L. The effects of thermal and oxidative degradation on the fatty acid composition of food plants and animals of western Canada: Implications for the identification of archaeological vessel residues. J. Archaeol. Sc. 1999, 26, 95-103.

11. Reber, E.A.; Hart, J.P. Pine resins and pottery sealing: Analysis of absorbed and visible pottery residues from central New York State. Archaeometry 2008, 50, 999-1017. [CrossRef]

12. Goldenberg, L.; Neumann, R.; Weiner, S. Microscale distribution and concentration of preserved organic molecules with carboncarbon double bonds in archaeological ceramics: Relevance to the field of residue analysis. J. Archaeol. Sci. 2014, 42, 509-518. [CrossRef]

13. Regert, M.; Bland, H.A.; Dudd, S.N.; van Bergen, P.F.; Evershed, R.P. Free and bound fatty acid oxidation products in archaeological ceramic vessels. Proc. R. Soc. B 1998, 265, 2027-2032. [CrossRef]

14. Craig, O.E.; Love, G.D.; Isaksson, S.; Taylor, G.; Snape, C.E. Stable carbon isotopic characterisation of free and bound lipid constituents of archaeological ceramic vessels released by solvent extraction, alkaline hydrolysis and catalytic hydropyrolysis. J. Anal. Appl. Pyrolysis 2004, 71, 613-634. [CrossRef]

15. Hammann, S.; Scurr, D.J.; Alexander, M.R.; Cramp, L.J.E. Mechanisms of lipid preservation in archaeological clay ceramics revealed by mass spectrometry imaging. Proc. Natl. Acad. Sci. USA 2020, 117, 14688-14693. [CrossRef] [PubMed]

16. Stern, B.; Heron, C.; Serpico, M.; Bourriau, J. A comparison of methods for establishing fatty acid concentration gradients across potsherds: A case study using Late Bronze Age Canaanite Amphorae. Archaeometry 2000, 42, 399-414. [CrossRef]

17. Hansel, F.A.; Bull, I.D.; Evershed, R.P. Gas chromatographic mass spectrometric detection of dihydroxy fatty acids preserved in the 'bound' phase of organic residues of archaeological pottery vessels. Rapid Commun. Mass Spectrom. 2011, 25, 1893-1898. [CrossRef] [PubMed]

18. Correa-Ascencio, M.; Evershed, R.P. High throughput screening of organic residues in archaeological potsherds using direct acidified methanol extraction. Anal. Methods 2014, 6, 1330-1340. [CrossRef]

19. Reber, E.A.; Dudd, S.N.; van der Merwe, N.J.; Evershed, R.P. Direct detection of maize in pottery residues via compound specific stable carbon isotope analysis. Antiquity 2004, 78, 682-691. [CrossRef]

20. Atalay, S.; Hastorf, C.A. Food, Meals, and Daily Activities: Food Habitus at Neolithic Çatalhöyük. Am. Antiq. 2006, 71, 283-319. [CrossRef]

21. Fritz, G.J. Feeding Cahokia: Early Agriculture in the North American Heartland; The University of Alabama Press: Tuscaloosa, AL, USA, 2019.

22. Mann, N. Meat in the human diet: An anthropological perspective. Nutr. Diet. 2007, 64, S102-S107. [CrossRef]

23. Melamed, Y.; Kislev, M.E.; Geffen, E.; Lev-Yadun, S.; Goren-Inbar, N. Acheulian plant food. Proc. Natl. Acad. Sci. USA 2016, 113, 14674-14679. [CrossRef] [PubMed] 
24. Mnich, B.; Mueller-Bieniek, A.; Nowak, M.; Wilczyński, J.; Pospuła, S.; Szostek, K. Terrestrial diet in prehistoric human groups from southern Poland based on human, faunal and botanical stable isotope evidence. J. Archaeol. Sci. Rep. 2020, $32,102382$. [CrossRef]

25. Reber, E.A.; Evershed, R.P. Ancient vegetarians? Absorbed pottery residue analysis of diet in the late Woodland and Emergent Mississippian periods of the Mississippi Valley. Southeast. Archaeol. 2006, 25, 110-120.

26. Bligh, E.G.; Dyer, W.J. A rapid method of total lipid extraction and purification. Can. J. Biochem. Physiol. 1959, 37, 911-917. [CrossRef]

27. Folch, J.; Lees, M.; Stanley, G.H.S. A simple method for the isolation and purification of total lipides from animal tissues. J. Biol. Chem. 1957, 226, 497-509. [CrossRef]

28. Reber, E.A.; Kelly, J.E.; Boswell, E.; Lane, C.S. Molecular evidence of changing foodways across the Mississippian transition at the George Reeves site (11S650). Southeast. Archaeol. 2020, 39, 71-88. [CrossRef] 